\title{
PENGARUH MORAL REASONING DAN \\ ETHICAL SENSITIVITY TERHADAP \\ PERSEPSI ETIS MAHASISWA AKUNTANSI \\ (Studi Pada Mahasiswa Akuntansi Universitas \\ Muhammadiyah Tangerang)
}

\author{
Riska Wahyu Febriani \\ Universitas Muhammadiyah Tangerang
}

\begin{tabular}{|c|c|}
\hline INFO ARTKEL & A B S T R A C T \\
\hline $\begin{array}{l}\text { Keyword: } \\
\text { Moral reasoning, } \\
\text { Ethical sensitivity, } \\
\text { Ethical perception }\end{array}$ & $\begin{array}{l}\text { This study aims to analyze the influence moral reasoning and ethical sensitivity } \\
\text { to ethical perception of accounting students. The population in this research is } \\
\text { SI active accounting students in University of Muhammadiyah Tangerang, with } \\
\text { amount I } 284 \text {, and the sample in this research are } 93 \text { people. This research } \\
\text { used is the purposive sampling method, while the data processing method used } \\
\text { multiple regression analysis and test interactions. This research used is the } \\
\text { purposive sampling method, while the data processing method used multiple } \\
\text { regression analysis. This research used a survey method that uses primary data } \\
\text { obtained from questionnaires distributed to respondents. The results of this } \\
\text { study indicate that the variables of moral reasoning and ethical sensitivity have } \\
\text { a positive and significant effect on the ethical perception of accounting students, } \\
\text { but only moral reasoning which has positive and significant impact, while the } \\
\text { ethical sensitivity has no effect on the ethical perception of accounting students. }\end{array}$ \\
\hline
\end{tabular}

I NT I SAR I

Penelitian ini bertujuan untuk menganalisis pengaruh moral reasoning dan ethical sensitivity terhadap persepsi etis mahasiswa akuntansi. Populasi dalam penelitian ini adalah mahasiswa akuntansi SI yang aktif di Universitas Muhammadiyah Tangerang, dengan jumlah 1284, sedangkan sampel dalam penelitian ini berjumlah 93 orang. Penentuan sampel yang menggunakan purposive sampling, sedangkan metode pengolahan data menggunakan analisis regresi berganda dan uji interaksi. Penelitian ini menggunakan metode survei yang menggunakan data primer yang diperoleh dari kuesioner yang dibagikan kepada responden. Hasil penelitian ini menunjukkan bahwa moral reasoning dan ethical sensitivity memiliki pengaruh positif dan signifikan terhadap persepsi etis mahasiswa akuntansi, tetapi hanya penalaran moral yang memiliki dampak positif dan signifikan, sedangkan ethical sensitivity tidak berpengaruh pada etika persepsi mahasiswa akuntansi. 


\section{PENDAHULUAN}

\section{Latar Belakang Masalah}

Di Indonesia, isu mengenai pelanggaran etika sejalan dengan terjadinya beberapa pelanggaran etika baik yang dilakukan oleh akuntan publik, akuntan internal, maupun akuntan pemerintah.

Pada saat ini, begitu banyak masalah yang terjadi yang turut serta melibatkan profesi akuntan. Sorotan yang diberikan kepada profesi ini disebabkan oleh beberapa faktor seperti praktik-praktik profesi yang mengabaikan standar akuntansi bahkan etika.

Pelanggaran etika oleh akuntan intern misalnya rekayasa data akuntansi untuk menunjukkan kinerja keuangan perusahaan agar tampak lebih baik, sedangkan pelanggaran etika yang dilakukan oleh akuntan pemerintah misalnya pelaksanaan pemeriksaan yang tidak semestinya (Nugrahaningsih, 2005).

Di Indonesia kasus pelanggaran etika cukup sering terjadi. Pada tahun 200I KPMGSiddharta Siddharta \& Harsono (KPMG-SSH) dan senior partner-nya, Sony B. Harsono dikeluarkan oleh SEC. Hal ini disebabkan karena PT Eastman Christensen (PTEC) meminta KPMG-SSH untuk menyuap pejabat kantor pajak Jakarta Selatan agar jumlah kewajiban pajak bagi PTEC menjadi serendah mungkin. Untuk menutupi tindak penyuapan tersebut, Harsono memerintahkan pegawainya agar mengeluarkan tagihan (invoice) atas nama KPMG. Tagihan tersebut kemudian dibuat tidak hanya untuk menutupi pembayaran uang suap kepada petugas kantor pajak, namun sekaligus fee atas imbal jasa KPMG-SSH bagi PTEC. Akibat tindak penyuapan ini, PTEC menerima hasil penghitungan pajak yang besarnya kurang lebih US $\$ 270$ ribu, padahal PTEC seharusnya membayar sekitar US\$ 3 juta.

Selain itu, pada tahun 2008 terjadi pelanggaran terhadap Standar Auditing (SA) Standar Profesional Akuntan Publik (SPAP) yang dilakukan oleh KAP Drs Tahrir Hidayat dan Akuntan Publik (AP) Drs Dody Hapsoro. Pelanggaran tersebut dilakukan dalam pelaksanaan audit atas laporan keuangan konsolidasi PT Pupuk Sriwidjaya (Persero) dan anak perusahaan tahun buku 2005. Akibat tindakannya tersebut, Menteri Keuangan Sri Mulyani melakukan pembekuan izin KAP Drs Tahrir Hidayat dan Akuntan Publik (AP) Drs. Dody Hapsor.

Perilaku etis dan pendidikan merupakan hal yang kritis masyarakat modern. Pendidikan akuntansi tentang etika sangat berpengaruh besar bagi mahasiswa akuntansi yang harus disampaikan dengan benar kepada mahasiswa akuntansi. Salah satu tujuannya adalah agar mahasiswa akuntansi dapat mengetahui, mengenal, dan mengerti nilainilai dan standar etik dalam profesi akuntansi.

Karakteristik individu seperti Moral Reasoning dan Ethical Sensitivity memiliki pengaruh terhadap individu dalam pengambilan keputusan mengenai tindakan etis. Welton dkk. (1994) menyatakan bahwa kemampuan individu dalam menyelesaikan dilema etika dipengaruhi oleh level penalaran moralnya. Menurut Rest (1994), semakin tinggi level penalaran moral seseorang akan semakin mungkin untuk berperilaku etis. Ethical Sensitivity sangat penting dimiliki oleh setiap individu untuk menilai kepekaan mereka terhadap norma-norma dan nilai-nilai yang ada baik di dalam maupun diluar lingkungan keberadaan mereka.

Mahasiswa akuntansi merupakan generasi penerus akuntan yang akan menggantikan profesinya di masa yang akan datang. Oleh karena itu, ilmu pengetahuan tentang perilaku etis sangat diperlukan sebagai bekal kelak ketika ia bekerja sebagai akuntan. Ilmu pengetahuan mengenai perilaku etis akuntan akan membentuk persepsi dan mempengaruhi kepribadian mahasiswa untuk berperilaku baik.

Mahasiswa tidak terlepas dari situasisituasi yang menuntutnya untuk memutuskan suatu penilaian atau pendapat moral, yaitu yang berhubungan dengan boleh atau tidak boleh suatu perilaku tertentu dilakukan. Fenomena yang terjadi pada Universitas Muhammadiyah Tangerang adalah kebiasaan mahasiswa yang cenderung ragu dalam memutuskan suatu sikap seperti boleh atau tidak bolehnya perilaku itu dilakukan.

Penelitian ini menggunakan obyek mahasiswa Program Studi Akuntansi di Universitas Muhammadiyah Tangerang. Pertimbangan pemilihan mahasiswa ini karena 
nantinya mereka akan memasuki dunia kerja, diharapkan dapat diketahui gambaran bagaimana cara mereka menyikapi bila seandainya mereka menghadapi suatu kasus dan cara mereka menghadapi kasus yang terjadi di tempat mereka bekerja.

\section{Rumusan Masalah}

Berdasarkan latar belakang masalah di atas, maka penelitian ini akan dirumuskan dalam beberapa pertanyaan sebagai berikut:

I. Apakah moral reasoning berpengaruh signifikan terhadap persepsi etis mahasiswa akuntansi?

2. Apakah ethical sensitivity berpengaruh signifikan terhadap persepsi etis mahasiswa akuntansi?

3. Apakah moral reasoning dan ethical sensitivity secara bersama-sama (simultan) berpengaruh signifikan terhadap persepsi etis mahasiswa akuntansi?

\section{TINJAUAN PUSTAKA}

\section{Persepsi Etis Mahasiswa Akuntansi}

Persepsi menurut Slameto (2010) adalah proses yang berkaitan dengan masuknya pesan atau informasi kedalam otak manusia, melalui persepsi manusia terus menerus mengadakan hubungan dengan lingkungannya.

Bertens (2002), merumuskan pengertian etika dalam tiga pengertian. Pertama, etika digunakan dalam pengertian nilai-nilai dan norma-norma moral yang menjadi pegangan bagi seseorang atau suatu kelompok dalam mengatur tingkah lakunya. Kedua, etika merupakan kumpulan asas atau nilai moral atau kode etik. Ketiga, etika merupakan ilmu yang mempelajari tentang sesuatu hal yang baik dan buruk.

Pendidikan mengenai pentingnya etika dalam profesi perlu diberikan pada mahasiswa akuntansi sejak dini sebagai tindakan antisipatif supaya nantinya calon akuntan ini dapat berperilaku etis ketika dihadapkan dengan dunia kerja.

Persepsi Etis Mahasiswa Akuntansi merupakan pandangan seorang mahasiswa akuntansi sebagai calon akuntan melalui suatu proses yang didapat dari pengalaman dan pembelajaran terkait dengan etika seorang akuntan, sehingga ia dapat memberikan penilaian apakah perilaku akuntan merupakan perilaku etis atau tidak etis.

\section{Moral Reasoning}

Moral adalah sikap mental dan emosional yang dimiliki oleh individu sebagai anggota kelompok sosial dalam melakukan tugas-tugas serta loyalitas pada kelompok (Falah, 2006).

Moral reasoning merupakan kesadaran moral yang menjadi faktor utama yang mempengaruhi perilaku moral dalam pengambilan keputusan etis. Moral reasoning merupakan sebuah proses penentuan benar atau salah yang dialami seseorang dalam mengambil suatu keputusan etis.

\section{Ethical Sensitivity}

Kemampuan seseorang profesional untuk berperilaku etis sangat dipengaruhi oleh sensitivitas indidvidu tersebut terhadap etika. Faktor yang penting dalam menilai perilaku etis adalah adanya kesadaran para individu bahwa mereka adalah agen moral. Kesadaran individu tersebut dapat dinilai melalui kemampuan untuk menyadari adanya nilai-nilai etika dalam suatu keputusan, inilah yang disebut sensitivitas etis (Andi, 20I3).

Sensitivitas etis (ethical sensitivity) dapat diartikan sebagai kesadaran individu dalam menilai perilaku etis. Kesadaran individu tersebut dapat dinilai melalui kemampuan untuk menyadari adanya nilai-nilai etis dalam suatu keputusan.

\section{Kerangka Pemikiran}

Perilaku etis menunjukkan perilaku seorang akuntan dan profesionalismenya, kemudian Selain memiliki moral reasoning, akuntan seharusnya juga memiliki ethical sensitivity yang tinggi, karena kinerja dari para akuntan sangat dipengaruhi oleh tingkat moral reasoning dan ethical sensitivity yang mereka punyai.

Mahasiswa dengan tingkat moral reasoning dan ethical sensitivity yang tinggi akan memiliki persepsi positif kepada akuntan yang mematuhi kode etik profesi akuntan dan akan memiliki persepsi negatif kepada akuntan yang melanggar kode etik profesi, 
Berdasarkan keterangan diatas maka kerangka konseptual penelitian tentang pengaruh moral reasoning dan ethical sensitivity terhadap minat persepsi etis mahasiswa akuntansi adalah

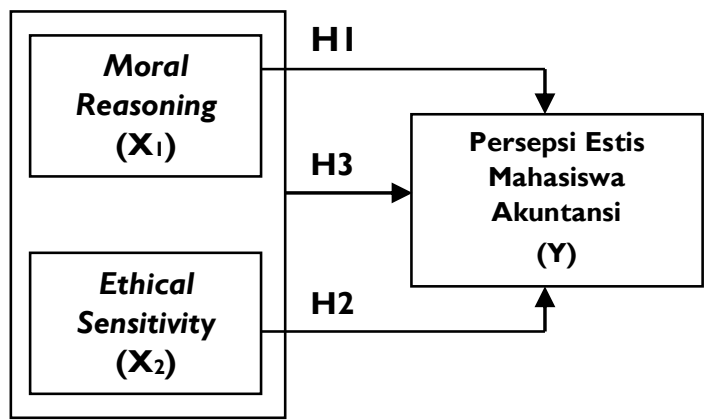

Gambar I. Kerangka Konseptual

\section{Hipotesis}

Berdasarkan latar belakang, rumusan masalah serta kerangka konseptual di atas maka dapatlah diberikan hipotesis dalam penelitian ini yaitu:

HI: Terdapat pengaruh positif dan signifikan moral reasoning terhadap persepsi etis mahasiswa akuntansi.

H2: Terdapat pengaruh positif dan signifikan ethical sensitivity terhadap persepsi etis mahasiswa akuntansi.

H3: Moral reasoning dan ethical sensitivity secara bersama-sama (simultan) mempengaruhi persepsi etis mahasiswa akuntansi.

\section{METODE PENELITIAN}

\section{Jenis Penelitian}

Jenis penelitian ini adalah explanatory research, yaitu penelitian yang bertujuan untuk menjelaskan kedudukan yang diteliti serta hubungan dan pengaruh antara satu dengan lain (Sugiyono, 2009).

\section{Variabel Penelitian}

Variabel penelitian adalah hal-hal yang dapat membedakan atau membawa variasi pada nilai (Sekaran, 20I4). Penelitian ini menggunakan dua variabel yaitu variabel independen dan variabel dependen.

I. Variabel dependen (variabel terikat)

Variabel dependen merupakan variabel yang menjadi pusat perhatian peneliti. Hakekat sebuah masalah, mudah terlihat dengan mengenali berbagai variabel dependen yang digunakan dalam sebuah model (Ferdinand, 2006). Dalam penelitian ini yang menjadi variabel dependen adalah persepsi etis mahasiswa akuntansi ( $\mathrm{Y}$ ).

2. Variabel independen (variabel bebas)

Variabel independen adalah variabel yang mempengaruhi variabel dependen, baik yang pengaruhnya positif maupun yang pengaruhnya negatif (Ferdinand, 2006). Dalam penelitian ini yang menjadi variabelvariabel independen adalah moral reasoning $\left(X_{1}\right)$ dan ethical sensitivity $\left(X_{2}\right)$.

\section{Definisi Operasional}

Definisi operasional dan skala pengukuran-nya yang digunakan dalam penelitian ini dijelaskan pada tabel berikut.

Tabel 3.I Definisi Operasional Variabel

\begin{tabular}{|c|c|c|}
\hline Variabel & $\begin{array}{c}\text { Definisi } \\
\text { Operasional }\end{array}$ & $\begin{array}{c}\text { Skala } \\
\text { Pengukuran }\end{array}$ \\
\hline $\begin{array}{l}\text { Moral } \\
\text { Reasoning } \\
\left(X_{1}\right)\end{array}$ & $\begin{array}{l}\text { Penalaran moral } \\
\text { pada setiap individu } \\
\text { sebagai wujud } \\
\text { individu tersebut } \\
\text { memahami }\end{array}$ & Skal Likert \\
\hline $\begin{array}{l}\text { Ethical } \\
\text { Sensitivity } \\
\left(\mathrm{X}_{2}\right)\end{array}$ & $\begin{array}{l}\text { Sikap etis yang } \\
\text { dilakukan dalam } \\
\text { keseharian dalam } \\
\text { melakukan sesuatu. }\end{array}$ & Skala Likert \\
\hline $\begin{array}{l}\text { Persepsi } \\
\text { Etis } \\
\text { Mahasiswa } \\
\text { Akuntansi } \\
\text { (Y) }\end{array}$ & $\begin{array}{l}\text { Persepsi mengenai } \\
\text { sikap dan perilaku } \\
\text { yang sesuai dengan } \\
\text { norma-norma sosial } \\
\text { yang diterima } \\
\text { secara umum } \\
\text { sehubungan dengan } \\
\text { tindakan-tindakan } \\
\text { yang bermanfaat }\end{array}$ & Skala Likert \\
\hline
\end{tabular}

Sumber: Diolah untuk penelitian ini, 2017

\section{Populasi dan Sampel}

Populasi adalah wilayah generalisasi yang terdiri atas objek atau subjek yang mempunyai kualitas dan karakteristik tertentu yang ditetapkan oleh peneliti untuk dipelajari dan kemudian ditarik kesimpulannya (Sugiyono, 2009).

Populasi dalam penelitian ini adalah seluruh mahasiswa aktif S-I program studi akuntansi di Universitas Muhammadiyah Tangerang (UMT) sebanyak 1284 orang.

Jumlah sampel mahasiswa didapatkan dengan menggunakan rumus Slovin Sebagai berikut: 
$n=\frac{N}{1+N(e)^{2}}=\frac{1284}{1+1284(0,1)^{2}}=\frac{1284}{13,84}=92,77$ dibulatkan 93

Keterangan :

$n$ : ukuran sampel

$N$ : ukuran populasi

e : kemungkinan ketidaktelitian karena kesalahan pengambilan sampel yang dapat ditolerir $(e=10 \%)$.

Dari hasil perhitungan sampel diatas maka jumlah sampel dalam penelitian ini sebanyak 93 responden.

Teknik pengambilan sampel yang digunakan dalam penelitian ini adalah melalui pendekatan non probability sampling yaitu purposive sampling. Sampel pada penelitian ini adalah mahasiswa aktif (tidak sedang cuti) yang telah menempuh masa studi lebih dari empat semester pada Program Studi Akuntansi Universitas Muhammadiyah Tangerang.

\section{Analisis Regresi Linear Berganda}

Secara umum analisis ini digunakan untuk meneliti pengaruh dari beberapa variabel independen (variabel $X$ ) terhadap variabel dependen (variabel Y) (Ghozali, 2006). Pada regresi berganda variabel independen (variabel $X)$ yang diperhitungkan pengaruhnya terhadap variabel dependen (variabel $Y$ ), jumlahnya lebih dari satu. Dalam penelitian ini, variabel independen adalah Moral Reasioning $\left(X_{1}\right)$ Ethical Sensitivity $\left(\mathrm{X}_{2}\right)$ sedangkan variabel dependen adalah Persepsi Etis Mahasiswa (Y) sehingga persamaan regresi bergandanya adalah:

$Y=a+b_{1} X_{1}+b_{2} X_{2}+e$

Dimana:

$\begin{array}{lll}\mathrm{Y} & : & \text { Persepsi Etis Mahasiswa } \\ \mathrm{a} & : & \text { Konstanta } \\ \mathrm{b}_{1}, \mathrm{~b}_{2}: & \text { Koefisien masing-masing faktor } \\ \mathrm{X}_{1}: & \text { Moral Reasioning } \\ \mathrm{X}_{2}: & \text { Ethical Sensitivity }\end{array}$

\section{Pengujian Hipotesis}

Untuk mengetahui pengaruh masingmasing variabel independen pada variabel terikat perlu dilakukan pengujian signifikansi dari masing-masing koefisien regresi yaitu dengan menggunakan Uji $t$ dan uji $F$.
Uji t didgunakan untuk mengetahui pengaruh variabel independen secara parsial terhadap variabel dependen, apakah pengaruhnya signifikan atau tidak (Priyatno, 2009).

Uji $F$ pada dasarnya menunjukan apakah semua variabel independen atau bebas yang dimasukan dalam model mempunyai pengaruh secara bersama-sama terhadap variabel dependen atau terikat (Priyatno, 2009).

\section{HASIL PENELITIAN}

\section{Analisis Regresi Berganda}

Berikut hasil perhitungan regresi linier berganda antara variabel moral reasoning $\left(X_{1}\right)$ dan ethical sensitivity $\left(X_{2}\right)$ terhadap persepsi etis mahasiswa ( $Y$ ). Melalui proses perhitungan SPSS 22 dapat diperoleh hasil sebagai berikut:

Tabel 4. I Hasil Pengolahan Data Regresi Linier Berganda

\begin{tabular}{|c|c|c|}
\hline \multirow[b]{2}{*}{ Model } & \multicolumn{2}{|c|}{$\begin{array}{c}\text { Unstandardized } \\
\text { Coefficients }\end{array}$} \\
\hline & $\mathrm{B}$ & Std. Error \\
\hline 1 (Constant) & 2.952 & 1.111 \\
\hline Moral Reasoning & .260 & .045 \\
\hline Ethical Sensitivity & -.022 & .058 \\
\hline
\end{tabular}

a. Dependent Variable: Persepsi Etis Mahasiswa

Sumber: Data primer diolah, 2017

Sehingga dari persamaan rumus regresi linier berganda dapat diperoleh hasil sebagai berikut:

$$
Y=2.952+0,260 X_{1}-0,022 X_{2}
$$

Hasil persamaan regresi berganda tersebut di atas memberikan pengertian bahwa:

- Nilai konstanta 2,952 mempunyai arti bahwa apabila variabel-variabel bebas yaitu moral reasoning dan ethical sensitivity itu konstan atau tidak berubah maka perubahan persepsi etis mahasiswa positif.

- $b_{1}$ (nilai koefisien regresi $X_{1}$ ) 0,260 mempunyai arti bahwa jika moral reasoning lebih ditingkatkan sedangkan variabel lain adalah tetap (konstan) maka persepsi etis mahasiswa juga akan meningkat.

- $b_{2}$ (nilai koefisien regresi $X_{2}$ ) $-0,022$ mempunyai arti bahwa jika ethical sensitivity diturunkan sedangkan variabel lain adalah 
tetap (konstan) maka persepsi etis mahasiswa akan meningkat.

\section{Analisis Koefisien Determinasi}

Koefisien determinasi digunakan untuk mengetahui seberapa besar variabilitas variabel independen dalam menjelaskan variabel dependen yang ditunjukkan oleh nilai $R$ square $\left(R^{2}\right)$ yaitu sebesar 0,274 artinya variabilitas variabel moral reasoning dan ethical sensitivity hanya mampu menjelaskan persepsi etis mahasiswa sebesar $27,4 \%$, sedangkan sisanya sebesar $72,6 \%$ dipengaruhi oleh variabilitas variabel lain yang tidak diteliti dalam penelitian ini. Hasil keluaran SPSS 22 dari Koefisien determinasi dapat dilihat pada tabel dibawah ini.

\section{Tabel 4.2 Koefisien Determinasi}

\begin{tabular}{|l|c|r|r|c|}
\hline \multicolumn{5}{|c|}{ Model Summary } \\
\hline Model & R & R Square & $\begin{array}{c}\text { Adjusted } \\
\text { R Square }\end{array}$ & $\begin{array}{c}\text { Std. Error of } \\
\text { the Estimate }\end{array}$ \\
\hline 1 & $.523^{\mathrm{a}}$ & .274 & .257 & 1.38943 \\
\hline
\end{tabular}

a. Predictors: (Constant), Ethical Sensitivity, Moral Reasoning

Sumber: Data primer diolah, 2017

\section{Pengujian Hipotesis}

Pengujian hipotesis dilakukan untuk mengetahui apakah persamaan regresi yang diperoleh tersebut dapat dipertanggung jawabkan atau tidak. Bila hasil analisis nanti menunjukkan bahwa persamaan regresi yang bersangkutan adalah signifikan atau dapat dipertanggung jawabkan, maka persamaan regresi tersebut dapat digunakan untuk meramalkan variabel $Y$ dan sekaligus untuk membuktikan hipotesis yang diajukan.

I. Pengujian Hipotesis Secara Parsial (Uji t)

Uji t digunakan untuk mengetahui pengaruh moral reasoning $\left(X_{1}\right)$ dan ethical sensitivity $\left(X_{2}\right)$ secara parsial terhadap persepsi etis mahasiswa $(Y)$,

Tabel 4.3 Uji Hipotesis Secara Parsial (Uji t)

\begin{tabular}{|c|c|c|c|c|c|}
\hline \multirow[b]{2}{*}{ Model } & \multicolumn{2}{|c|}{$\begin{array}{l}\text { Unstandardized } \\
\text { Coefficients }\end{array}$} & \multirow{2}{*}{$\begin{array}{c}\text { Standardized } \\
\text { Coefficients } \\
\text { Beta }\end{array}$} & \multirow[b]{2}{*}{$\mathrm{t}$} & \multirow[b]{2}{*}{ Sig. } \\
\hline & $B$ & $\begin{array}{l}\text { Std. } \\
\text { Error }\end{array}$ & & & \\
\hline $\begin{array}{ll} & \text { (Constant) }\end{array}$ & 2.952 & 1.111 & & 2.657 & .009 \\
\hline Moral Reasoning & 260 & .045 & .523 & 5.816 & .000 \\
\hline Ethical Sensitivity & -.022 & .058 & -.033 & -.371 & .712 \\
\hline
\end{tabular}

Sumber: Data primer diolah, 2017

Hasil pengujian hipotesis menunjukkan bahwa nilai $t$ hitung untuk moral reasoning adalah 5,816 dengan signifikansinya sebesar 0,000; sedangkan pada taraf signifikansi sebesar
0,025 dengan degree of freedom ( $d f$ ) sebesar $=$ 90 diperoleh nilai t tabel sebesar I,987 sehingga nilai $\mathrm{t}$ hitung $=5,816>$ nilai $\mathrm{t}$ tabel $=1,987$. Dengan demikian menunjukkan bahwa moral reasoning $\left(X_{1}\right)$ berpengaruh positif signifikan terhadap persepsi etis mahasiswa (Y).

Hasil pengujian hipotesis menunjukkan bahwa nilai $t$ hitung untuk ethical sensitivity adalah $-0,37$ I dengan signifikansinya sebesar 0,7I2; sedangkan pada taraf signifikansi sebesar 0,025 dengan degree of freedom (df) sebesar = 90 diperoleh nilai $t$ tabel sebesar I,987 sehingga nilai $\mathrm{t}$ hitung $=0,37 \mathrm{I}<$ nilai $\mathrm{t}$ tabel $=\mathrm{I}, 987$. Dengan demikian menunjukkan bahwa ethical sensitivity $\left(X_{2}\right)$ berpengaruh negatif dan tidak signifikan terhadap persepsi etis mahasiswa $(Y)$.

Dengan demikian dapat disimpulkan bahwa hanya moral reasoning yang secara parsial berpengaruh terhadap persepsi etis mahasiswa akuntansi, sedangkan ethical sensitivity secara parsial tidak berpengaruh terhadap persepsi etis mahasiswa akuntansi.

\section{Pengujian Hipotesis Secara Simultan (uji F)}

Uji $\mathrm{F}$ digunakan untuk mengetahui pengaruh moral reasoning $\left(X_{1}\right)$ dan ethical sensitivity $\left(X_{2}\right)$ secara bersama-sama (simultan) terhadap persepsi etis mahasiswa (Y).

\section{Tabel 4.4 Uji Hipotesis Secara Simultan (Uji} F)

\begin{tabular}{|c|c|c|c|c|c|}
\hline \multicolumn{6}{|c|}{ ANOVA $^{a}$} \\
\hline Model & $\begin{array}{c}\text { Sum of } \\
\text { Squares }\end{array}$ & df & $\begin{array}{c}\text { Mean } \\
\text { Square }\end{array}$ & $\mathrm{F}$ & Sig. \\
\hline 1 Regression & 65.416 & $\overline{2}$ & 32.708 & 16.943 & $.000^{\mathrm{b}}$ \\
\hline Residual & 173.745 & 90 & 1.931 & & \\
\hline Total & 239.161 & 92 & & & \\
\hline
\end{tabular}

b. Predictors: (Constant), Ethical Sensitivity, Moral Reasoning

Sumber: Data primer diolah, 2017

Hasil perhitungan yang telah dilakukan diperoleh nilai $F$ hitung adalah sebesar 16,943 sedangkan degree of freedom (df) pada angka 2 dan 90 dalam tabel $F$ diperoleh nilai sebesar 3,098 sehingga nilai $F$ hitung sebesar 16,943> nilai $\mathrm{F}$ tabel $=3,098$. Hal ini menunjukkan bahwa terdapat pengaruh signifikan secara bersamasama antara moral reasoning $\left(X_{1}\right)$ dan ethical sensitivity $\left(\mathrm{X}_{2}\right)$ secara bersama-sama (simultan) terhadap persepsi etis mahasiswa $(\mathrm{Y})$. 


\section{PEMBAHASAN}

\section{Pengaruh positif dan signifikan moral reasoning terhadap persepsi etis mahasiswa akuntansi}

Hasil penelitian menunjukkan bahwa terdapat pengaruh positif dan signifikan moral reasoning terhadap persepsi etis mahasiswa akuntansi. Hasil pengujian hipotesis menunjukkan bahwa nilai $t$ hitung untuk moral reasoning adalah 5,816 dengan signifikansinya sebesar 0,000 dan nilai a sebesar 0,260; sedangkan pada taraf signifikansi sebesar 0,025 dengan $\mathrm{df}$ sebesar $=90$ diperoleh nilai $\mathrm{t}$ tabel sebesar 2,00I sehingga nilai $t$ hitung $=5,816>$ nilai $\mathrm{t}$ tabel $=\mathrm{I}, 987$. Dengan demikian menunjukkan bahwa terdapat pengaruh signifikan antara moral reasoning $\left(X_{I}\right)$ terhadap persepsi etis mahasiswa akuntansi(Y).

Hipotesis pertama (HI) menyebutkan bahwa terdapat pengaruh positif dan signifikan moral reasoning terhadap persepsi etis mahasiswa akuntansi, berhasil didukung oleh data atau dengan kata lain hipotesis diterima. Semakin tinggi tingkat moral reasoning yang dimiliki mahasiswa akuntansi, maka persepsi etis mahasiswa akuntansi akan semakin baik. Apabila mahasiswa akuntansi memiliki moral reasoning yang tinggi, maka ia akan memberikan penalaran moral jika di lingkungannya terjadi perilaku yang menyimpang atau tidak etis dan dengan adanya moral reasoning yang dimiliki maka ia akan memberikan persepsi bahwa tindakan tersebut tidak etis dan akan mengambil tindakan-tindakan yang etis. Begitu juga dengan perilaku etis maupun tidak etis yang dilakukan oleh para akuntan, mahasiswa akuntansi dengan moral reasoning yang dimiliki maka ia akan dapat menilai atau memberikan persepsi etis kepada para akuntan atas perilakunya tersebut.

\section{Pengaruh negatif dan tidak signifikan ethical sensitivity terhadap persepsi etis mahasiswa Akuntansi}

Hasil penelitian menunjukkan bahwa terdapat pengaruh negatif dan tidak signifikan ethical sensitivity terhadap persepsi etis mahasiswa akuntansi. Hasil pengujian hipotesis menunjukkan bahwa nilai $t$ hitung untuk ethical sensitivity adalah 0,37 I dengan signifikansinya sebesar 0,712 dan nilai a sebesar -0,022; sedangkan pada taraf signifikansi sebesar 0,025 dengan $\mathrm{df}$ sebesar $=90$ diperoleh nilai $\mathrm{t}$ tabel sebesar 2,00I sehingga nilai $t$ hitung $=0,37 \mathrm{I}<$ nilai $\mathrm{t}$ tabel $=\mathrm{I}, 987$. Dengan demikian menunjukkan bahwa terdapat pengaruh tidak signifikan antara ethical sensitivity $\left(\mathrm{X}_{2}\right)$ terhadap persepsi etis mahasiswa akuntansi ( $Y$ ).

Hipotesis kedua (H2) menyebutkan bahwa terdapat pengaruh positif dan signifikan ethical sensitivity $\left(\mathrm{X}_{2}\right)$ terhadap persepsi etis mahasiswa akuntansi, tidak berhasil didukung oleh data atau dengan kata lain hipotesis ditolak. Artinya ethical sensitivity tidak berpengaruh terhadap persepsi etis mahasiswa akuntansi.

\section{Pengaruh moral reasoning dan ethical sensitivity secara bersama-sama (simultan) terhadap persepsi etis mahasiswa akuntansi}

Berdasarkan hasil dari analisis pengaruh moral reasoning dan ethical sensitivity terhadap persepsi etis mahasiswa akuntansi melalui uji $F$ dapat diketahui bahwa variabel-variabel bebas (moral reasoning dan ethical sensitivity) mempunyai pengaruh secara bersama-sama terhadap variabel terikatnya (persepsi etis mahasiswa akuntansi). Hal ini dapat ditunjukkan melalui hasil uji $F$ dengan nilai $F$ hitung sebesar 16,943 dengan P-value sebesar 0,000 . Nilai $F$ hitung yang diperoleh menunjukkan nilai yang lebih besar dari $\mathrm{F}$ tabel ( $\mathrm{F}$ hitung $>\mathrm{F}$ tabel; 16,943>3,098) dan nilai signifikan yang lebih kecil dari $5 \%(0,000<0,05)$, dapat disimpulkan bahwa variabel-variabel bebas dalam penelitian ini (moral reasoning dan ethical sensitivity) secara bersama-sama mempengaruhi variabel terikatnya (persepsi etis mahasiswa akuntansi).

Hipotesis empat (H4) menyebutkan bahwa terdapat pengaruh positif dan signifikan moral reasoning dan ethical sensitivity secara bersama-sama (simultan) terhadap persepsi etis mahasiswa akuntansi berhasil didukung oleh data atau dengan kata lain hipotesis diterima. Persepsi etis mahasiswa akuntansi akan semakin baik bila dikaitkan dengan semakin baiknya moral reasoning dan ethical sensitivity yang semakin tinggi.

\section{PENUTUP}

\section{Kesimpulan}

Berdasarkan penelitian yang telah dilakukan maka dapat diperoleh kesimpulan sebagai berikut: 
I. Terdapat pengaruh positif dan signifikan antara moral reasoning dan ethical sensitivity secara bersama-sama (simultan) terhadap persepsi etis mahasiswa akuntansi.

2. Terdapat pengaruh positif dan signifikan moral reasoning terhadap persepsi etis mahasiswa akuntansi. Artinya apabila moral reasoning tersebut meningkat maka hal itu akan meningkatkan persepsi etis mahasiswa akuntansi

3. Terdapat pengaruh negatif dan tidak signifikan etchical sensitivity terhadap persepsi etis mahasiswa Akuntansi. Artinya data penelitian tidak mendukung ethical sensitivity berpengaruh terhadap persepsi etis mahasiswa akuntansi.

\section{Saran}

Berdasarkan hasil penelitian serta hal-hal yang terkait dengan keterbatasan penelitian ini, maka dapat diberikan saran-saran sebagai berikut:

I. Penelitian akan lebih baik apabila tidak hanya menggunakan kuesioner saja tetapi dilengkapi dengan teknik wawancara atau metode lain agar bisa mendapatkan data yang lebih valid dan sesuai dengan kenyataan yang sebenarnya.

2. Penelitian ini masih terbatas pada moral reasoning dan ethical sensitivity, untuk peneliti selanjutnya dapat dilakukan penambahan variabel penelitian yang juga berpengaruh terhadap persepsi etis mahasiswa akuntansi.

\section{DAFTAR PUSTAKA}

Bertens, K. 2002, Etika. Jakarta: Gramedia Pustaka.

Falah. 2006, Pengaruh Budaya Etis Organisasi dan Orientasi Etis terhadap Sensitivitas Etis. Tesis Program Pascasarjana Akuntansi. Universitas Diponegoro. Semarang.

Ferdinand, Augusty. 20II, Metode Penelitian Manajemen Pedoman Penelitian untuk Penulisan Skripsi, Tesis, dan Disertasi Ilmu Manajemen. Edisi 3. AGF Books. Fakultas Ekonomika dan Bisnis Universitas Diponegoro. Semarang.
Ghozali, Imam. 2006, Aplikasi Analisis Multivariate dengan Program SPSS. Badan Penerbit UNDIP. Semarang.

Nugrahaningsih, P. 2005, Analisis perbedaan perilaku etis auditor di KAP dalam etika profesi (Studi terhadap peran faktor-faktor individual: locus of control, lama pengalaman kerja, gender, dan equity sensitivity). SNA VIII, Solo, I5- I6 September 2005.

Priyatno, Duwi. 2009, SPSS untuk Analisis Korelasi, Regresi, dan Multivariate. Yogyakarta: Gava Media.

Rest, J. R. 1994, Background: Theory and Research. In J. R. Rest, \& D. Narvaez, Moral Development in the Professions: Phsychology and Applied Ethics (p.2). New Jersey: Lawrence Erlbaum Associates, Inc.

Sekaran, Uma. 2014, Metodologi Penelitian untuk Bisnis (Research Methods for Business), Buku I, Edisi 4. Jakarta: Salemba Empat.

Slameto. 2010, Belajar dan Faktor-faktor yang Mempengaruhinya. Jakarta: Rineka Cipta.

Sugiyono. 2009, Metode Penelitian Bisnis. Bandung: Alfabeta.

Welton, Ralph E., R. Michael Lagrone dan James R. Davis. 1994, Promoting The Moral Development of Accounting Graduate: an Instructional Design and Assessment. Accounting Education, 3 (I), 35-50. 